九州大学学術情報リポジトリ

Kyushu University Institutional Repository

\title{
Studies on the Papermaking Properties of Hydroxyethylated Kraft Pulps from Mangrove Woods
}

Bachman, Yos Tunggara

Laboratory of Polymer Chemistry of Woody Materials, Faculty of Agriculture, Kyushu University

Higuchi, Mitsuo

Laboratory of Polymer Chemistry of Woody Materials, Faculty of Agriculture, Kyushu University

Morita, Mitsuhiro

Laboratory of Polymer Chemistry of Woody Materials, Faculty of Agriculture, Kyushu University

Sakata, Isao

Laboratory of Polymer Chemistry of Woody Materials, Faculty of Agriculture, Kyushu University

https://doi.org/10.5109/23744

出版情報：九州大学大学院農学研究院紀要. 26 (2/3)，pp.121-138，1982-02. Kyushu University バージョン：

権利関係: 
J. Fac. Agr., Kyushu Univ., 26 (2 • 3), 121-138 (1982)

\title{
Studies on the Papermaking Properties of Hydroxyethylated Kraft Pulps from Mangrove Woods
}

\author{
Yos Tunggara Bachman*, Mitsuo Higuchi, \\ Mitsuhiro Morita and Isao Sakata** \\ Laboratory of Polymer Chemistry of Woody Materials, Faculty \\ of Agriculture, Kyushu University 46-08, Fukuoka 812
}

(Received November 5, 1981)

\begin{abstract}
Mangrove wood fibers generally lack flexibility because of their thick cell walls. Due to this defect pulps prepared from Mangrove woods form weak and bulky papersheets. Hydoxyethylation was applied to the Mangrove pulp in order to improve its papermaking properties. A remarkable difference was observed between the behavior of hydroxyethylated Mangrove pulps and that of a hydroxyethylated domestic hardwood pulp studied for comparison. A very slight hydroxyethylation (i. e., hydroxyethylation with the use of $1 \%$ ethylene oxide on the basis of pulp weight) brought about a considerable increase in the sheet strength properties of the Mangrove pulps, while higher levels of hydroxyethylation which caused a marked improvement of the papermaking properties for the domestic hardwood pulp brought deterioration on the Mangrove pulps. Scanning electron microscopy revealed that the slightly hydroxyethylated Mangrove pulp fibers were finely fibrillated by refining and suffered remarkable deformation in papersheet formation, while the highly hydroxyethylated fibers suffered little fibrillation and deformation. Results of some other investigations suggest that a partial extraction of hemicelluloses from the thick cell walls contribute to the increase in the flexibility of the fibers and a part of the effect of the slight hydroxyethylation can be attributed to this effect.
\end{abstract}

\section{INTRODUCTION}

Tropical forests occurring along the coasts and in salt-soiled swamps consist predominantly of trees called generically Mangrove. The growing stock of Mangrove, which comprises many species of trees belonging mainly to Rhyzophoracea family, can not be ignored, and it is desired to utilize the Mangrove woods.

As Mangrove woods are similar in chemical composition to hardwoods (broad leaved woods) occurring in temperate zone (Koeppen and Cohen, 1955; Koeppen, 1958) and they generally have large bulk densities, a merit is found in manufacturing pulps. However, Mangrove pulps, except those made from some species of trees of minor growing stock, have a problem in papersheet

* Present adderss : Faculty of Forestry, Mulawarman University, JL. Belibis-Sidomulyo, Samarinda-East Kalimantan, Indonesia.

** Reprint request should be addressed to this author. 
strengths. Although Mangrove wood fibers are not so different from temperate zone hardwood fibers in length and width, their cell walls are very thick. On account of this morphological specificity Mangrove wood fibers lack the flexibility which plays a very important role in papersheet formation. The strength of paper mainly depends on inter-fiber cohesion which arises from hydrogen bonds developed between hydroxyl groups on the fiber interfaces. But before this hydrogen bonds can be effective there should be contact. The flexibility of fibers controls the fiber-to-fiber contact area.

Chemical modification of pulp is one of the principal ways for improving papersheet strengths. Starting with Richter (1936), many workers have studied hydroxyethylation of fibers, and it is known that cotton linters and softwood kraft pulps become more flexible by hydroxyethylation resulting in a marked improvement of handsheet strength properties (Ward, 1960; Thomas, 1966 ; Ward et al., 1967 ; Didwania, 1969 ; Ward et al., 1969).

Although there is enough information about hydroxyethylated softwood kraft pulp, we can not directly apply it to hardwood pulp, especially to Mangrove pulp, because of considerable differences in chemical and morphological properties between softwood pulp and hardwood pulp.

The main purpose of the present study is to clarify how the pulp and papersheet properties change by the application of the hydroxyethylation to the Mangrove pulps of high cell-wall thickness.

\section{MATERIALS AND METHODS}

\section{Mangrove wood chips}

A mixture of Mangrove wood chips was received from Chuetsu Pulp Industry Co., Ltd. The original Mangrove woods were imported from Indonesia being species unidentified and in a state of the mixture of various Mangrove woods. The mixed Mangrove chips are used occasionally by mixing with domestic hardwood chips in pulp and paper industry in Japan. Identification was tried on the chips, and it was found that the chips were composed of Bruguiera sp., Rhywphora sp., Avicenia sp., and a few of unidentified species of Mangrove woods.

\section{Laboratory-made Mangrove pulp}

The Mangrove chips were cooked in a laboratory digester under the following cooking conditions.

$\begin{array}{lc}\left.\text { Active alkali (as } \mathrm{Na}_{2} \mathrm{O}, \mathrm{g} / l\right) & 40 \\ \text { Sulfidity ( } \% \text { ) } & 25 \\ \text { Liquor to wood ratio (ml/g) } & 5 \\ \text { Maximum (final) temperature (“C) } & 170 \\ \text { Time to the maximum temperature (min) } & 90 \\ \text { Time at the maximum temperature (min) } & 90\end{array}$

The cooked chips were washed, disintegrated by hand, and screened with a laboratory vibrating screen. The average yield of the kraft pulp was $43.6 \%$ and that of the reject materials was $0.8 \%$. The Kappa number determined 
was 15.3. The bleaching of pulp was carried out using a five-stage bleaching sequence (Chlorination : Alkali extraction : Chlorine dioxide treatment: Alkali extraction : Chlorine dioxide treatment). The brightness of the bleached pulp was 79.3 .

\section{Factory-made Mangrove pulp}

An unbeaten bleached kraft pulp was received from Nihon Kako Seishi Co., Ltd. The original Mangrove woods were unidentified.

\section{Domestic hardwood pulp}

An unbeaten bleached kraft pulp was received from Chuetsu Pulp Industry Co., Ltd. This pulp was made for commercial use from a mixture of domestic hardwood chips composed mainly of Buna (Fagus crenata) chips.

\section{Pulp treatments}

\section{Hydroxyethylation}

Before the reaction with ethylene oxide, pulps were steeped in $4 \%$ aqueous $\mathrm{NaOH}$ for 20 minutes, and then squeezed centrifugally to adjust the alkaline liquor content of the pulp mats to $100 \sim 150 \%$ on the basis of pulp weight. The pulp mats were then disintegrated in order to achieve the reaction between ethylene oxide and pulp fibers uniformly.

Hydroxyethylation was carried out by use of a rotary evaporator. A weighed amount of the alkali-pretreated pulp was placed in a $1,000-\mathrm{ml}$ roundbottomed flask immersed in a constant temperature bath. The air in the flask was evacuated, and then a weighed amount of ethylene oxide was introduced by vaporization. The reaction was allowed to proceed for 3 hours at $40^{\circ} \mathrm{C}$ under continuous stirring.

The hydroxyethylated pulps were neutralized with aqueous acetic acid solutions and washed with deionized water.

\section{Alkali treatnaent}

As hydroxyethylation is carried out on alkali-pretreated pulps and alkali itself can affect the pulp properties, alkali treatment was carried out as a reference.

Pulps were steeped in various concentration levels of aqueous $\mathrm{NaOH}$ solutions for 20 minutes at room temperature, and then neutralized with acetic acid and washed with deionized water.

\section{Addition of plasticizer}

Diethylene glycol and a polyethylene glycol were tested as plasticizers for the Mangrove pulps. Two methods were adopted for the addition of the plasticizers.

Method 1: A desired amount of $0.1 \%$ or $1 \%$ aqueous solution of diethylene glycol (or polyethylene glycol) was added to the pulp slurry of about 0.02 $\%$ pulp consistency in a TAPPI standard handsheet machine before sheet formation.

Method 2: A desired amount of $0.1 \%$ or $1 \%$ aqueous solution of the plasticizer was sprayed onto a wet handsheet which had been pressed under a pressure of $3.5 \mathrm{~kg} / \mathrm{cm}^{2}$ for 5 minutes to squeeze out the excess water. After 
1 minute's standing the handsheet was pressed again under a pressure of 3.5 $\mathrm{kg} / \mathrm{cm}^{2}$ for 2 minutes.

\section{Handsheet preparation}

Pulps were refined in a PFI mill to develop the freeness to $400 \mathrm{ml}$ Canadian standard freeness (CSF).

Handsheets were made according to TAPPI standard $\mathrm{T} 205 \mathrm{~m}-58$, and conditioned at $20^{\circ} \mathrm{C}$ and $65 \% \mathrm{RH}$ prior to testing.

\section{Testing procedures}

\section{Morphological measurements}

The measurement of fiber length, fiber diameter, cell lumen width, and cell wall thickness was carried out on wood and pulp preparations by use of a light microscope. Fiber classification of pulps was carried out in a Mc-Nett classifier with the use of $16,24,48,80$, and 150 mesh screens according to TAPPI standard T $234 \mathrm{~m}-60$.

\section{Swelling volume measurement}

The values of swelling volume of pulps were estimated by a centrifugal water retention method according to Thode et al. (1960).

\section{Handsheet properties measurements}

TAPPI methods were used to test the handsheets for basis weight, thickness, density, burst strength, tensile strength, folding endurance, tear strength, and surface strength. The equilibrium moisture content was determined by weighing the handsheet samples after 5 day's standing at $20^{\circ} \mathrm{C}$ and $65 \% \mathrm{RH}$. The roughness of sheet surfaces was measured by use of a KosakaSE-4 type surface roughness meter (Kosaka Laboratory Ltd.). Scanning electron microscopy was also adopted for the surface observation.

\section{RESULTS}

\section{Morphological properties of the pulps}

Table 1 shows the fiber dimesions measured on the Mangrove chips, the laboratory-made Mangrove pulp (designated as $\mathrm{M}-\mathrm{BK} \mathrm{P}-\mathrm{L}$ ), the factory-made Mangrove pulp (designated as M-BKP-F), and the domestic hardwood pulp (designated as L-BKP).

As can be seen in the Table, the Mangrove pulps are rather longer than the domestic hardwood pulp, while there is little differerence in fiber diameter. However, it must be noted that the Mangrove pulps are smaller in lumen diameter and larger in cell wall thickness.

According to Runkel's classification (Runkel, 1949) the Mangrove pulps are classified as thick-walled fibers (2W/l>unity) which are unsuitable for papermaking.

Differences in morphological properties between the two Mangrove pulps are very little notwithstanding the different sources of the pulps. 
Table 1. Morphological properties of wood fibers and vessels.

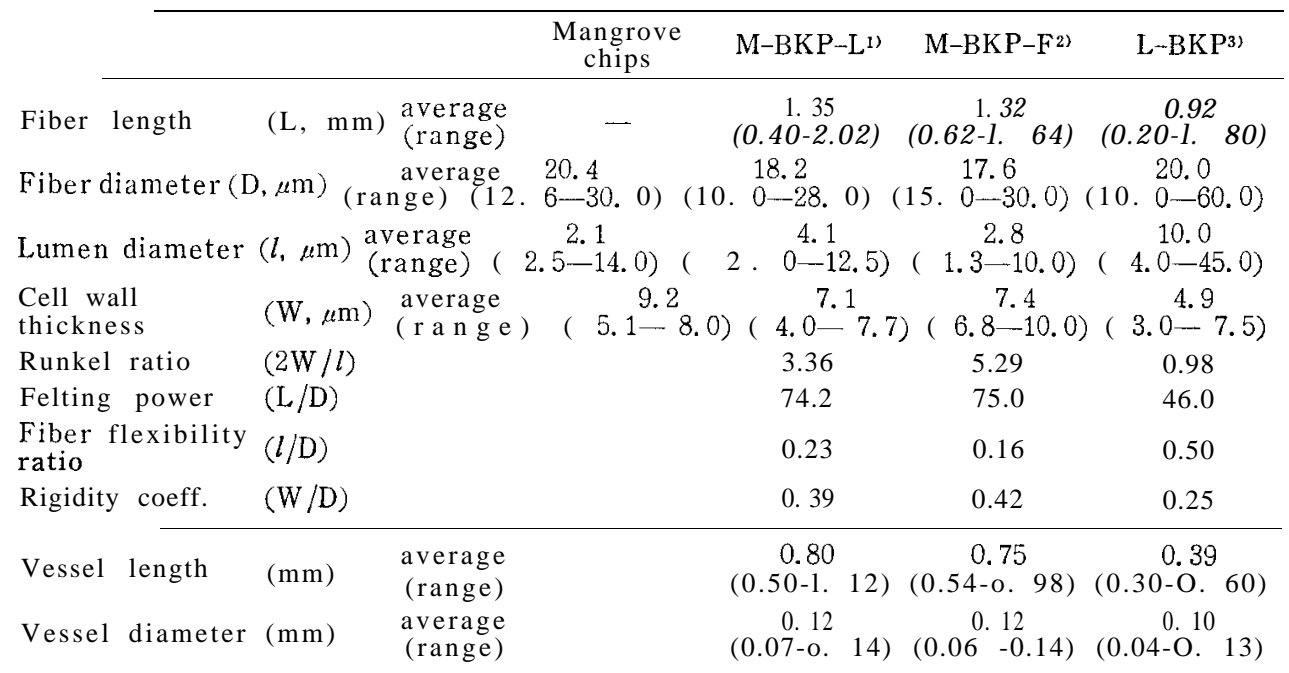

1): Bleached kraft pulp made from the Mangrove chips in the laboratory.

2): Bleached kraft pulp made from Mangrove chips in a factory.

3): Bleached kraft pulp made from domestic hardwood chips in a factory.

Effects of hydroxyethylation and of alkali treatment on the refining and sheet strength properties of the pulps

1. Hydroxyethylation with high addition levels of ethylene oxide

In the first place, as marked improvements in refining and sheet strength properties were obtained in a preliminary investigation in which the domestic hardwood pulp was hydroxyethylated by being presteeped in $4 \%$ aqueous $\mathrm{NaOH}$ and then reacted with $10 \sim 30 \%$ (on the basis of pulp weight) ethylene oxide, the Mangrove pulps were hydroxyethylated under the same conditions and compared with the domestic hardwood pulp.

Fig. 1 shows the changes in refining property caused by the hydroxyethylation. The ordinate is the revolution number of the PFI mill required for developing the pulp freeness to $400 \mathrm{ml} \mathrm{CSF}$, and the abscissa is the amount of ethylene oxide used in the preparation of the hydroxyethylated pulps.

Fig. 2 shows the changes in some of the sheet strength properties caused by the hydroxyethylation.

As can be seen in the Figures, while the domestic hardwood pulp became easier to be refined and its sheet strength properties increased with an increase in the amount of ethylene oxide added, the Mangrove pulp became harder to be refined and its sheet strength properties tended to deteriorate with an increase in the level of hydroxyethylation.

Although this result was unexpected, from scanning electron microscopy and some other investigations on the hydroxyethylated Mangrove pulps, those investigations will be described later, a suggestion was obtained that a lower level of hydroxyethylation was preferable for the Mangrove pulp. Therefore, 


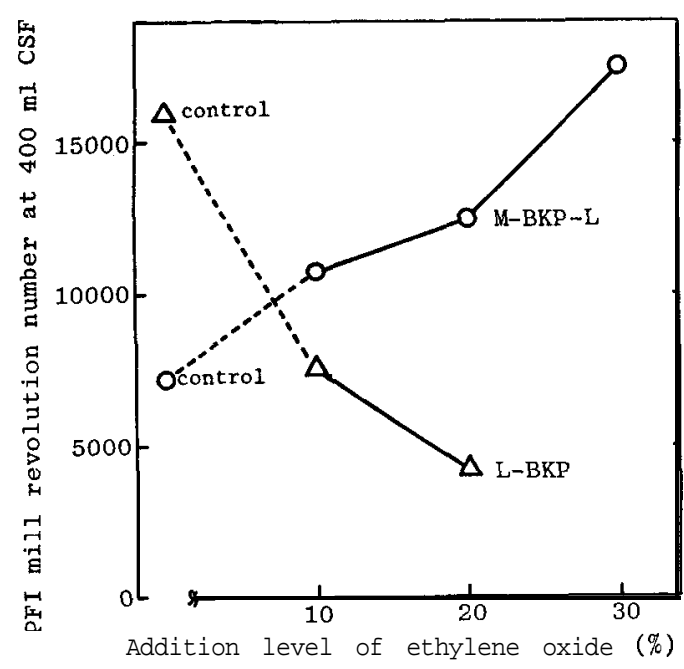

Fig. 1. Effect of high levels of hysroxyethylation on pulp beating.

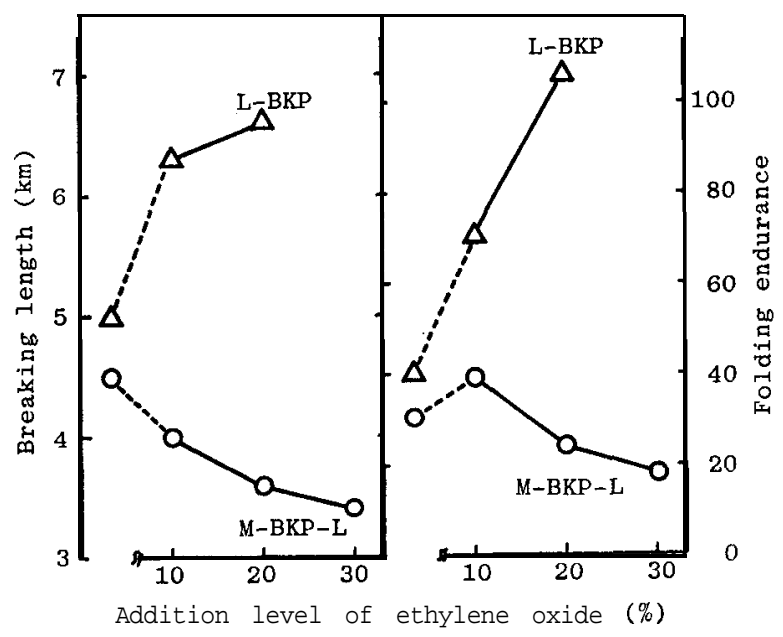

Fig. 2. Effect of high levels of hydroxyethylation on sheet strength properties.

the following investigations were carried out on the hydroxyethylated Mangrove pulps prepared by using low addition levels of ethylene oxide. Incidentally, no substantial difference was found between the behavior of the two Mangrove pulps, M-BKP-L and M-BKP-F, in refining and sheet strength examinations. Therefore, the data on M-BKP-L were presented in this paper as representatives.

2. Hydroxyethylation with low addition levels of ethylene oxide

The Mangrove pulp was hydroxyethylated in the same way described above 
except for the addition levels of ethylene oxide.

Fig. 3 shows the change in the refining property, and Fig. 4 shows the changes in sheet strength properties caused by the low levels of hydroxy-

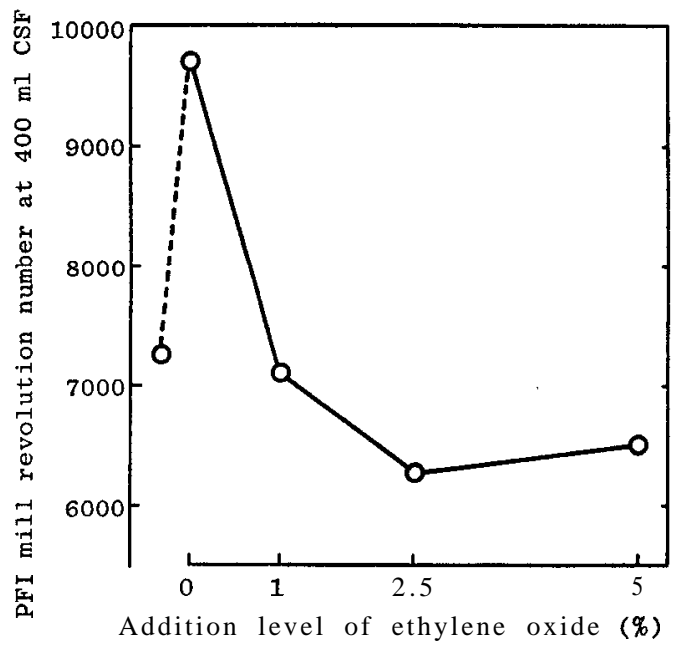

Fig. 3. Effect of low levels of hydroxyethylation on pulp beating. Pulp: M-BKP-L.

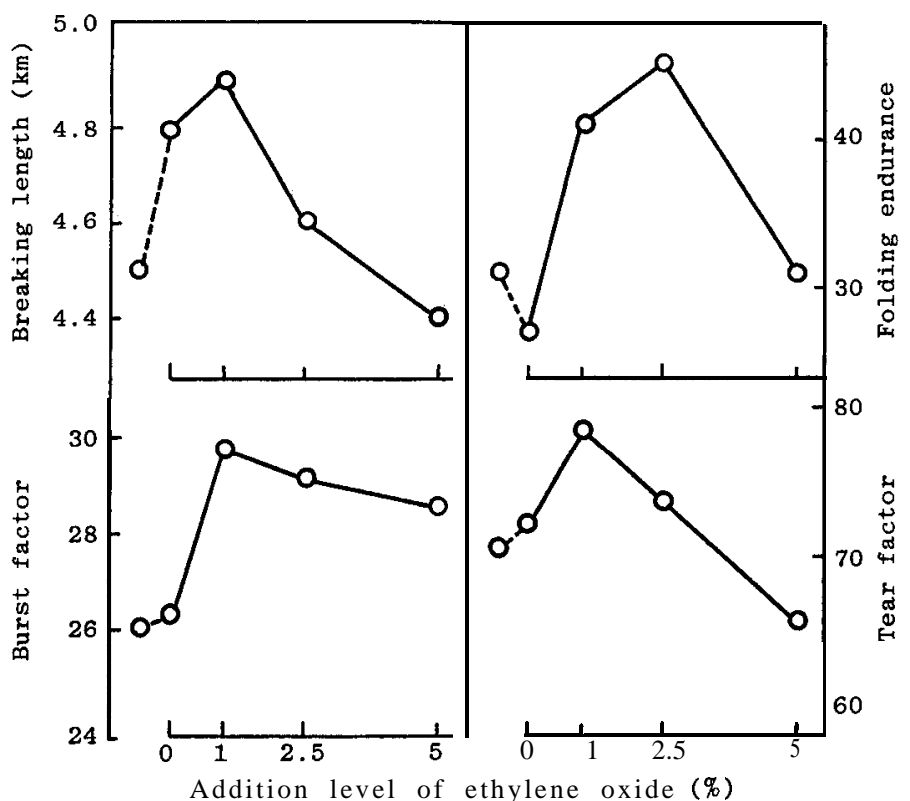

Fig. 4. Effect of low levels of hydroxyethylation on sheet strength properties. Pulp : M-BKP-L. 
ethylation. It must be noted that the samples of $0 \%$ ethylene oxide addition were those presteeped in aqueous $\mathrm{NaOH}$, while the control samples were those untreated.

As Fig. 3 shows, the Mangrove pulp became easier to be refined as the addition level of ethylene oxide increased up to $2.5 \%$, and then tended to become harder to be refined at higher levels of ethylene oxide addition.

Fig. 4 shows that the sheet strength properties can be improved when the Mangrove pulp is hydroxyethylated very slightly. It may be noted that tear factor also increased by the slight hydroxyethylation.

It can be also seen in the Figures that alkali presteeping itself seems to have some effect on the refining and sheet strength properties.

\section{Alkali treatment}

As Fig. 5 shows, the Mangrove pulp became harder to be refined by the alkali treatment.

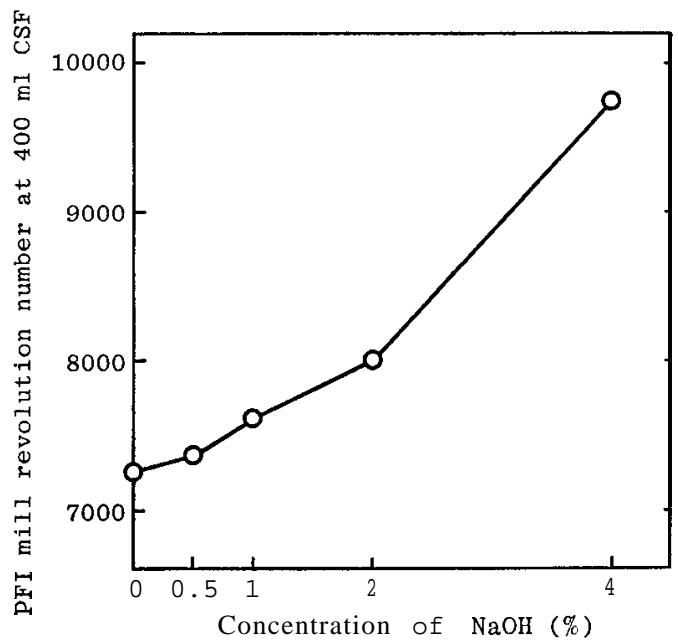

Fig. 5. Effect of alkali treatment on pulp beating. Pulp: M-BKP-L.

On the other hand, as can be seen in Fig. 6, breaking length, folding endurance and burst factor increased as the concentration of $\mathrm{NaOH}$ increased up to about $2 \%$ and then tended to decrease at higher levels of alkali treatment.

Effects of hydroxyethylation and of alkali treatment on the swelling of the Mangrove pulp

Swelling volume, as a measure of the deformability of fibers, was measured by a centrifugal water retention method after the pulps had been refined to $400 \mathrm{ml} \mathrm{CSF}$.

As shown in Fig. 7, hydroxyethylation with $1 \%$ ethylene oxide increased the swelling volume by a factor of about 3 . Higher levels of hydroxyethyla- 


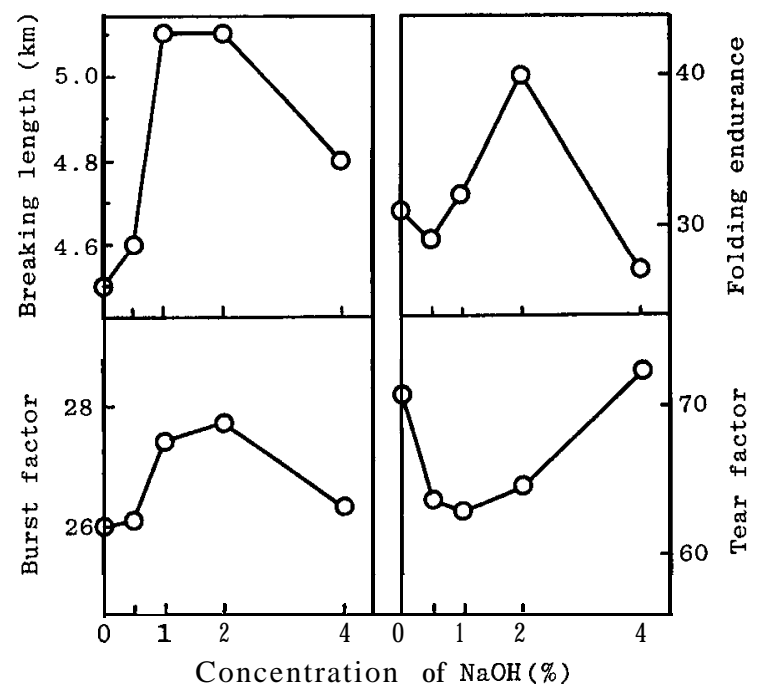

Fig. 6. Effect of alkali treatment on sheet strength properties. Pulp MBKP-L.

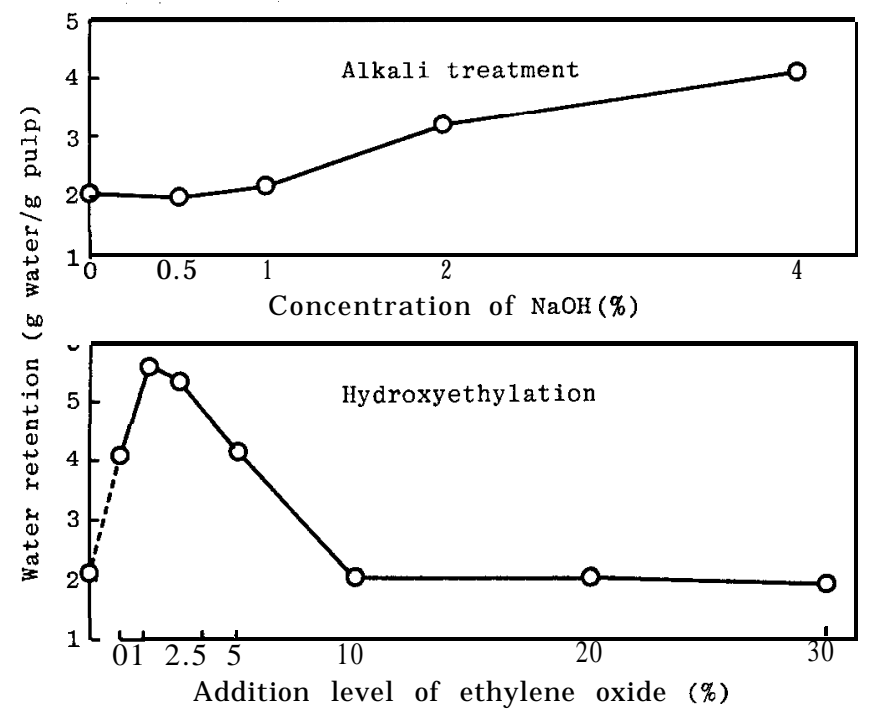

Fig. 7. Effect of hydroxyethylation and of alkali treatment on the swelling volume of M-BKP-L. Pulp freeness: $400 \mathrm{ml} \mathrm{CSF}$.

tion, however, decreased the swelling volume, while the alkali treatment increased it with an increase in the concentration of $\mathrm{NaOH}$.

Effect of hydroxyethylation on the fiber length distribution and fibrillation of the Mangrove pulp at refining

Fiber classification was carried out on three samples of Mangrove pulp, a 
control, a sample hydroxyethylated with $1 \%$ ethylene oxide, and a sample hydroxyethylated with $30 \%$ ethylene oxide, after the samples had been refined to $400 \mathrm{ml}$ CSF.

Fig. 8 shows that the low level of hydroxyethylation made the fibers more susceptible to cutting, while the high level of hydroxyethylation exhibited an inverse effect.

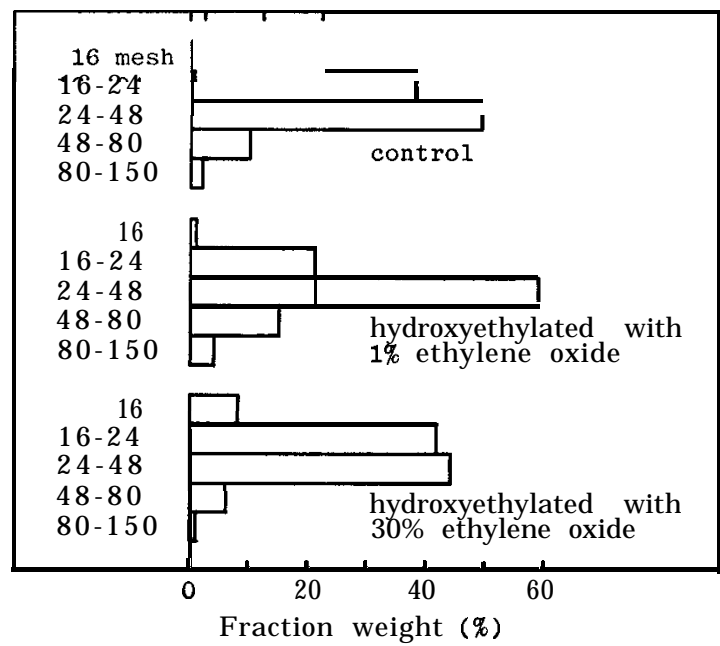

Fig. 8. Fiber classification of refined hydroxyethylated M-BKP-L. Pulp freeness : $400 \mathrm{ml} \mathrm{CSF}$.

Electron micrographs obtained by applying scanning electron microscopy on handsheets provide a closer look at fiber surfaces of these samples. Figs. 9, 10 and 11 show that the fibers hydroxyethylated with $1 \%$ ethylene oxide were fibrillated most finely. It must be noted that the fibers hydroxyethylat. ed with $30 \%$ ethylene oxide have smooth surfaces as if they have suffered no beating.

\section{Effect of hydroxyethylation on sheet density}

Fig. 12 shows the change in handsheet density caused by the hydroxyethylation. Hydroxyethylation of the Mangrove pulp with $1 \%$ ethylene oxide increased the handsheet density. However, the handsheet density decreased as the level of hydroxyethylation increased.

Fig. 13 shows the cross sectional figures of the handsheets. As can be seen in this Figure, the fibers hydroxyethylated with $1 \%$ ethylene oxide were deformed remarkably resulting in the most dense conformation.

\section{Effect of hydroxyethylation on sheet surface strength}

The surface strengths of the handsheets were determined by wax-picking tests. A similar tendency to that of sheet density can be seen in Fig. 14. 

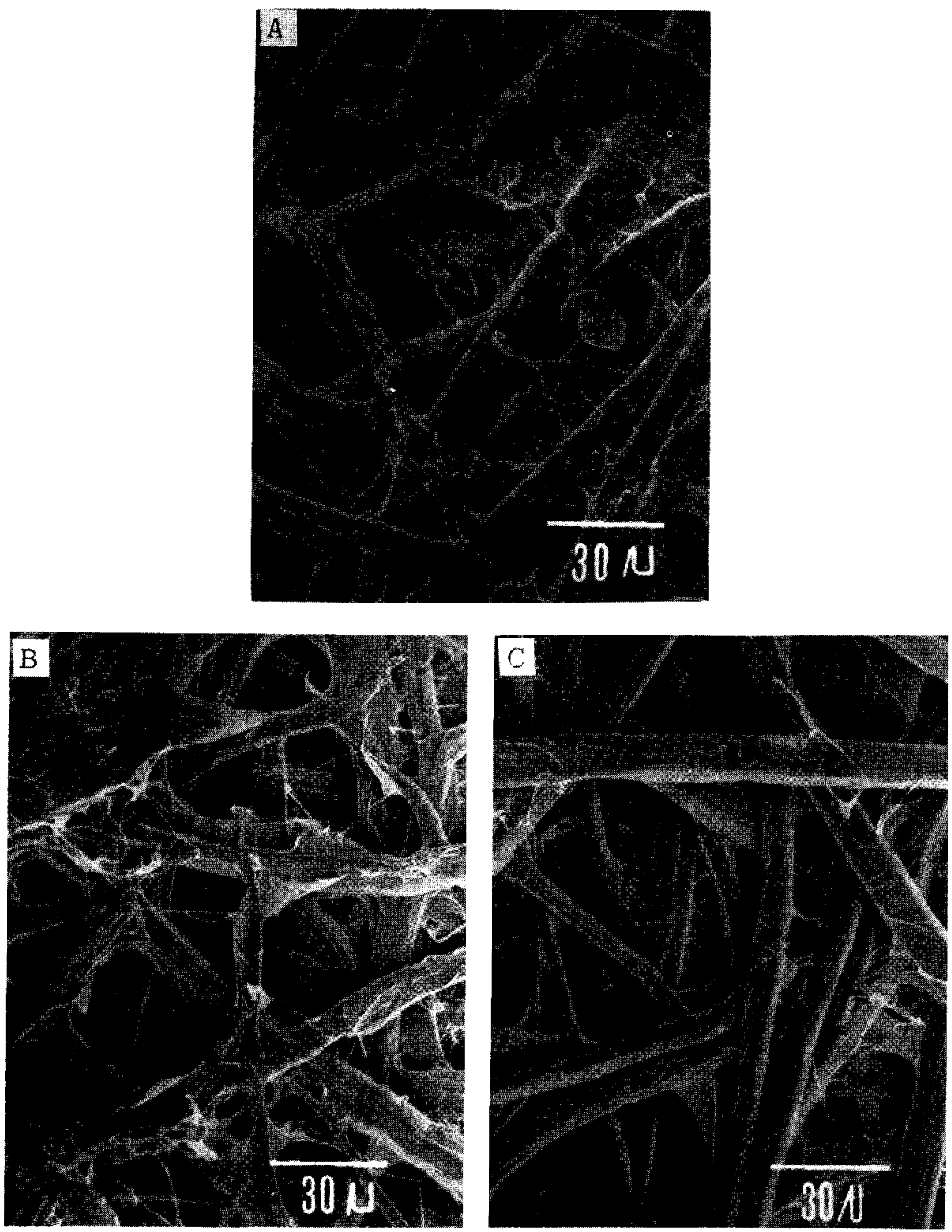

Fig. 9. Electron micrographs of refined M-BKP-L fibers (magnifification: $300 \times$ ). A: control (untreated fibers). B: hydroxyethylated with $1 \%$ ethylene oxide. C: hydroxyethylated with $30 \%$ ethylene oxide. 

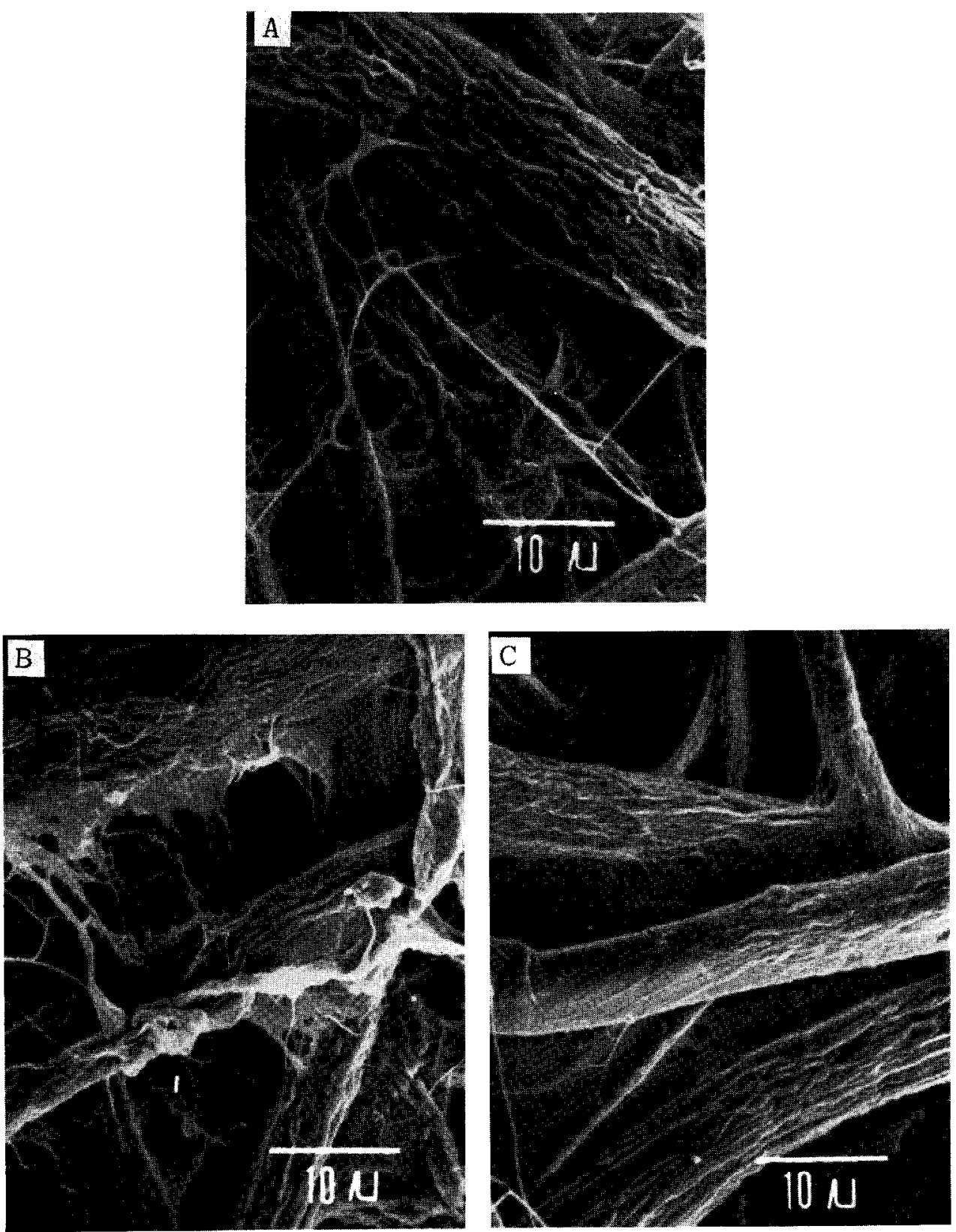

Fig. 10. Electron micrographs of refined M-BKP-L fibers (magnification: $1000 \mathrm{X})$. A, B, C: the same as in Fig. 9. respectively. 

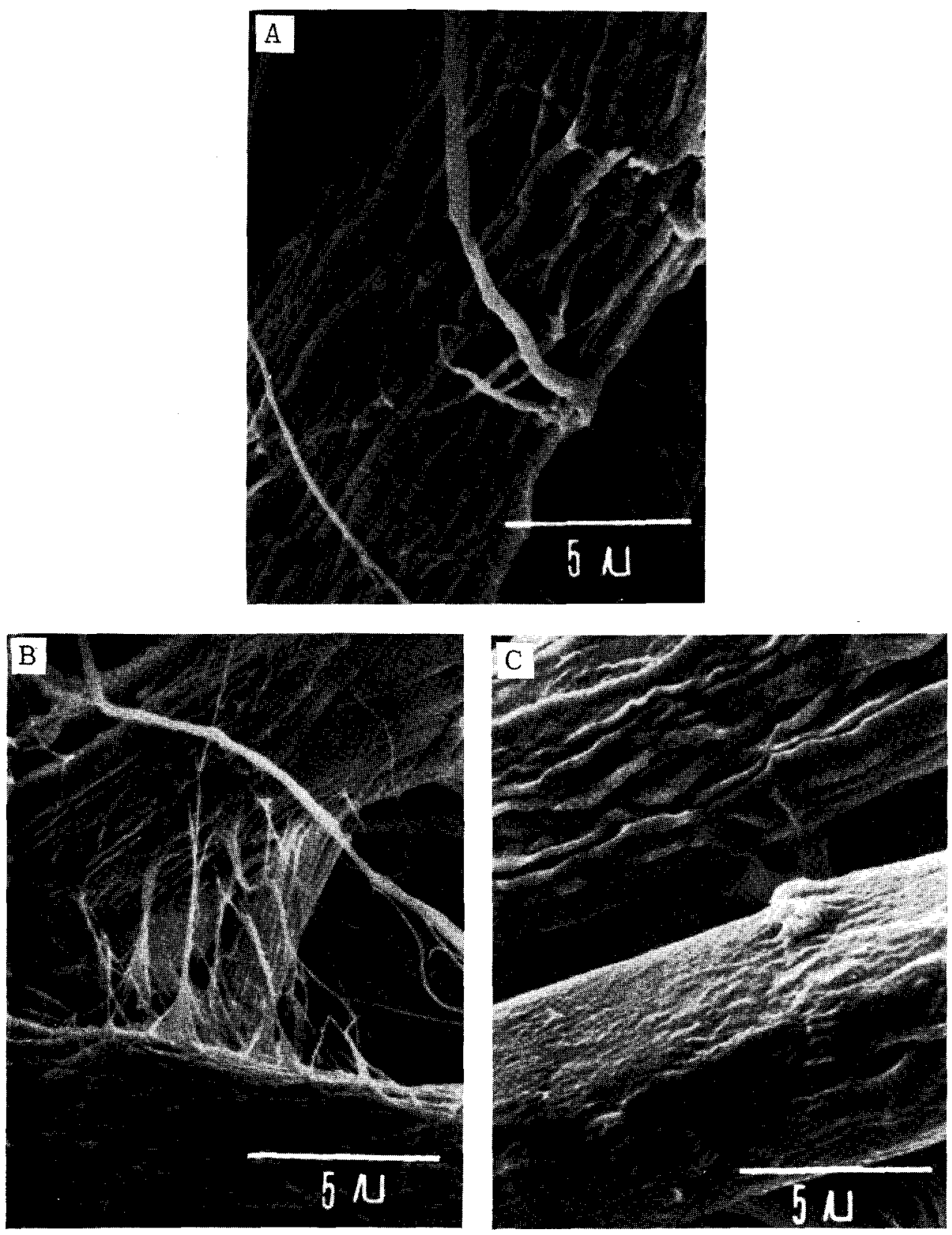

Fig. 11. Electron micrographs of refined M-BKP-L fibers (magnification: $3000 \mathrm{X})$. A, B, C: the same as in Fig. 9. respectively. 


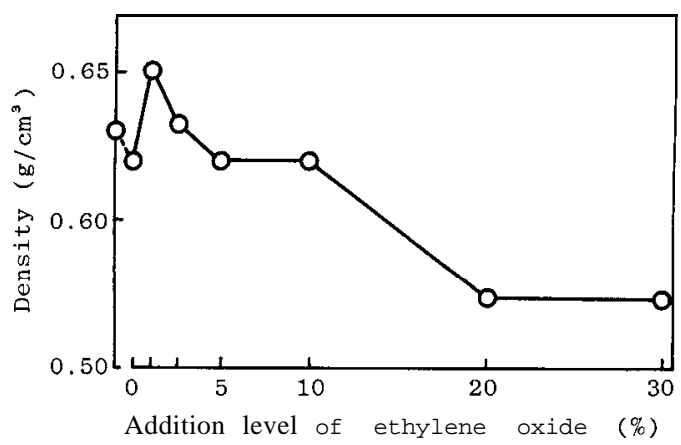

Fig. 12. Effect of hydroxyethylation on sheet density. Pulp: M-BKP-L, $400 \mathrm{ml} \mathrm{CSF}$.

Effect of hydroxyethylation on sheet surface smoothness

Fig. 15 shows the value of $\mathbf{R} \mathbf{c l a}$ (center line average roughness) of the handsheets. As can be seen in this Figure, sheet surface smoothness increased by hydroxyethylation with $1 \%$ ethylene oxide, and then decreased as the level of hydroxyethylation increased.

Effect of hydroxyethylation on the equilibrium moisture content of sheets

As Fig. 16 shows, the equilibrium moisture content increased by hydroxyethylation with $1 \%$ ethylene oxide and then decreased as the level of hydroxyethylation increased.

Solubility of hydroxyethylated Mangrove pulps in aqueous alkali solutions

Fig. 17 shows the changes in the content of substances soluble in $5 \%$ and in $10 \%$ aqueous $\mathrm{NaOH}$ solutions caused by the hydroxyethylation. The amount of $5 \% \mathrm{NaOH}$-soluble substances decreased to about $1 / 3$ by hydroxyethylation with $1 \%$ ethylene oxide, and then tended to recover gradually as the level of hydroxyethyiation increased. It must be noted that alkali-presteeping itself decreased the amount of $5 \% \mathrm{NaOH}-$ soluble substances to about $1 / 2$. These losses may be attributed to the loss of hemicelluloses in the process of hydroxyethylation.

On the other hand, the amount of $10 \% \mathrm{NaOH}$-soluble substances increased as the level of hydroxyethylation increased, although it decreased by alkalipresteeping and by hydroxyethylation with 196 ethylene oxide. This increase may be attributed to the increase in the amount of highly hydroxyethylated cellulosic components.

Effect of plasicizer addition on sheet strength properties

The addition of diethylene glycol and of polyethylene glycol caused little improvement in handsheet strength properties.

\section{DISCUSSION}

As can be seen in the above results, the effect of hydroxyethylation on 

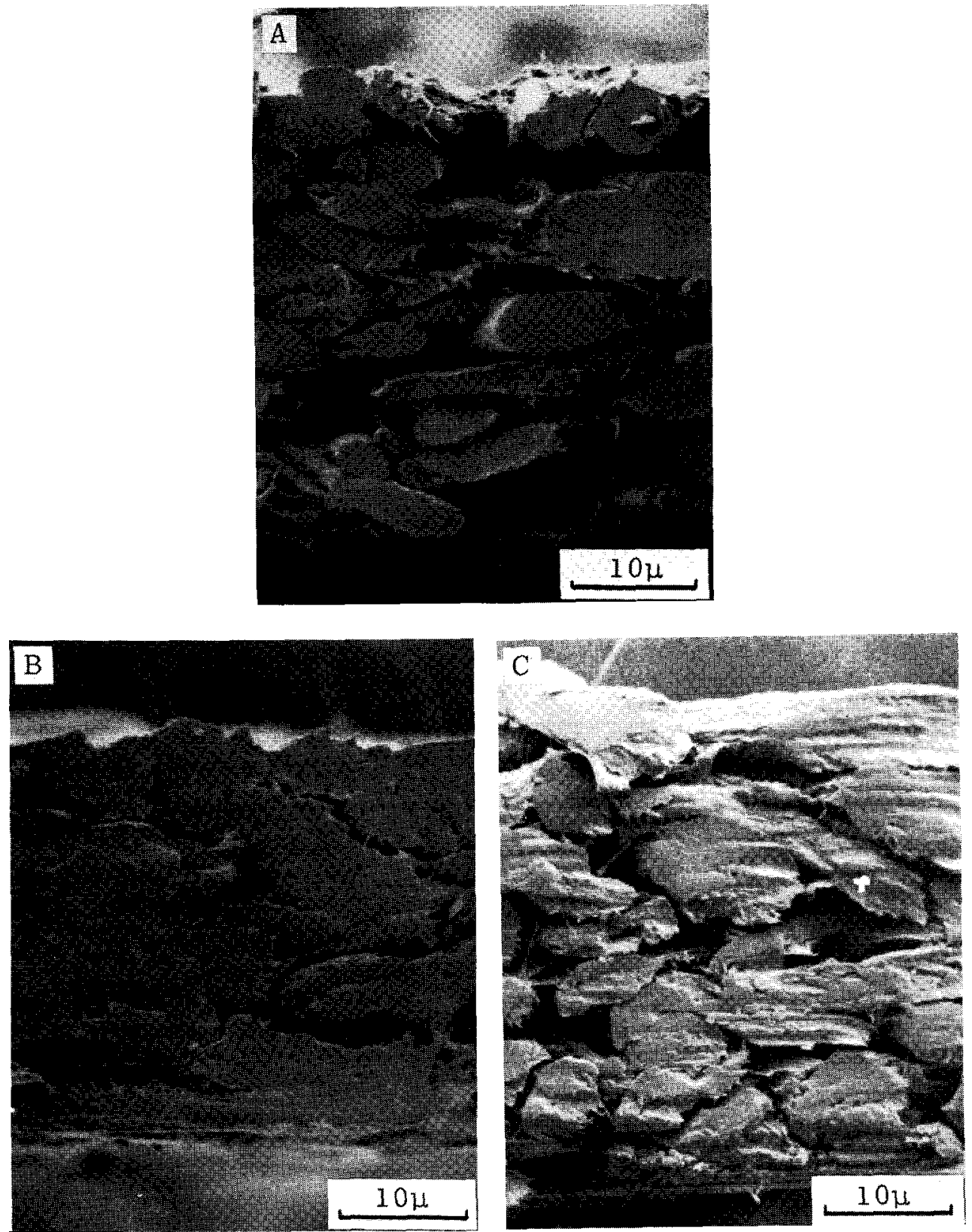

Fig. 13. Electron micrographs of sheet cross-sections. (magnification : $1000 \times$ ). A: sheet prepared from control (untreated) M-BKP-L. B: sheet prepared from M-BKP-L hydroxyethylated whith $1 \%$ ethylene oxide. C: sheet prepared from M-BKP-L hydroxyethylated with $30 \%$ ethylene oxide. 


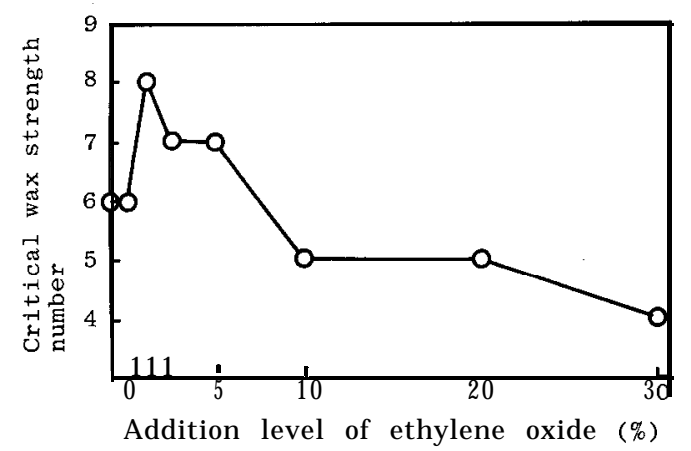

Fig. 14. Effect of hydroxyethylation on sheet surface strength. Pulp: MBKP-L, 400ml CSF.

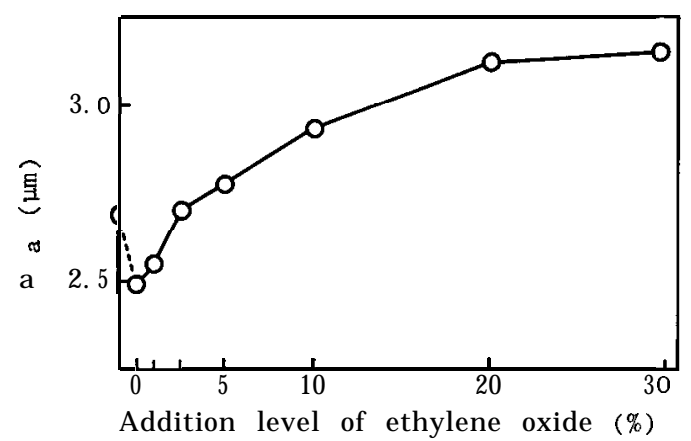

Fig. 15. Effect of hydroxyethylation on sheet surface roughness. Pulp: M-BKP-L, $400 \mathrm{ml} \mathrm{CSF}$.

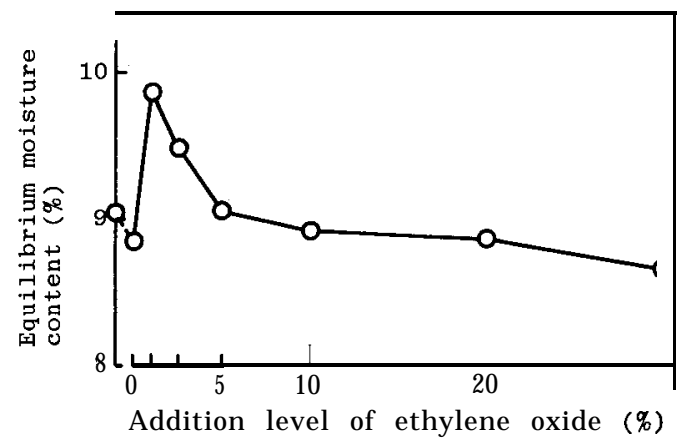

Fig. 16. Effect of hydroxyethylation on the equilibrum moisture content of papersheets. Pulp: M-BKP-L, $400 \mathrm{ml}$ CSF. 


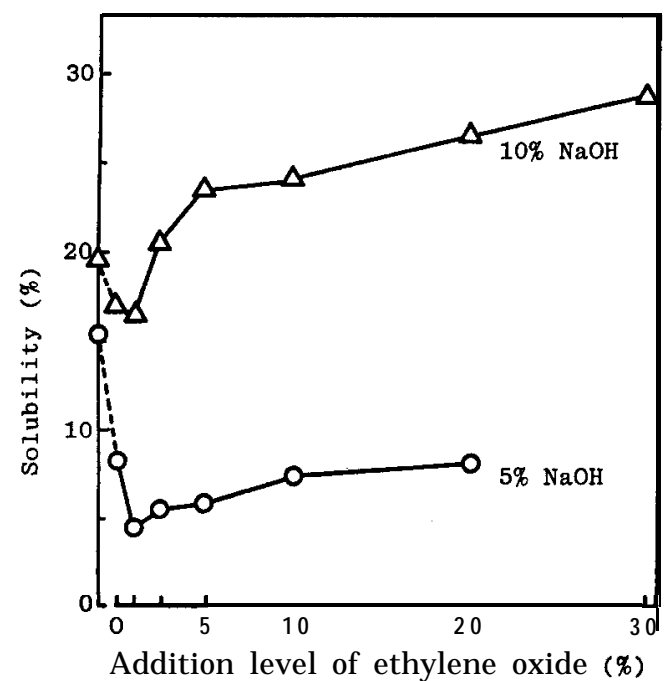

Fig. 17. Solubility of hydroxyethylated Mangrove pulps in aqueous $\mathrm{NaOH}$ solutions.

the papermaking properties of the Mangrove pulp differs from that of the domestic hardwood pulp. The Mangrove pulp was improved by a very slight level of hydroxyethylation, and, however, it deteriorated by higher levels of hydroxyethylation which caused a marked improvement for the domestic hardwood pulp.

Electron micrographs showed that the Mangrove pulp fibers hydroxyethylated with $1 \%$ ethylene oxide were finely fibrillated by refining and suffered remarkable deformation in sheet formation, while the control fibers, although they were considerably fibrillated by refining, suffered lesser deformation in sheet formation. The results of the measurement of the swelling volume of the fibers, sheet density, sheet surface smoothness, sheet surface strength and the equilibrium moisture content of sheets coincide with the result of the electron microscopic observation.

It may be said that the increase in the sheet strength properties caused by the slight hydroxyethylation is ascribable to the increase in the deformability of the refined pulp fibers.

The cause of the increase in the deformability of the slightly hydroxyethylated Mangrove pulp fibers has not been thoroughly clarified yet. However, as the result on the measurement of alkali-solubility of the fibers suggests, it seems likely that a partial extraction of hemicelluloses from the fiber cell walls contributes to the increase in the deformability. Although hemicelluloses play an important role in papersheet formation as an adhesive for fiber-to-fiber bonding, the loosening of microfibrils caused by the partial extraction of hemicelluloses seems to bring about the improvement of sheet strength properties overcoming the demerit of losing the adhesive. This may be due to the high thickness and rigidness of the fiber cell walls. 
The fact that a moderate alkali treatment of the Mangrove pulp caused a considerable improvement in sheet strength properties also supports the idea described above. However, there is a difference between the effect of alkali treatment and that of the slight hydroxyethylation. The alkali treatment made the pulp harder to be refined, while the slight hydroxyethylation made the pulp easier to be refined. It is apparent that the slight hydroxyethylation has some effect in addition to the partial extraction of hemicelluloses. However, the detailed information on that action is still lacking.

The deterioration of the sheet strength properties of the Mangrove pulp by the higher levels of hydroxyethylation may be attributed to the inferior state of refining. As the electron micrographs showed, the Mangrove pulp fibers hydroxyethylated with high addition levels of ethylene oxide suffered little fibrillation even after they had been refined to $400 \mathrm{ml} \mathrm{CSF}$. It seems likely that the fiber surface becomes half-soluble in water by the higher levels of hydroxyethylation and this swollen layer acts as a lubricant to reduce the frictional resistance in the refining process.

\section{ACKNOWLEDGEMENTS}

The authors wish to thank all members of staff of the Department of Forest Products, Faculty of Agriculture, Kyushu University for providing facilities for carring out experiments. The authors also wish to express their gratitude to Chuetsu Pulp Industry Co., Ltd. and Nihon Kako Seishi Co., Ltd. for supplying the Mangrove woods and pulps.

\section{REFERENCES}

Didwania, H. P. 1969 The mechanism of strength increases in paper on hydroxyethylation of fibers. Tappi, 52: 1511-1517

Koeppen, A. V. 1958 Pulping studies on Eucalyptus Deglupta Bl.,Bruguiera Parvifora Wight. and Arn., Avicennia Marina (Forsk.) Vierh. Tappi, 41: 460-464

Koeppen, A. V. and W. E. Cohen 1955 Pulping studies of five species of a mangrove association. Australian J. Appl. Sci., 5: 105-116

Richter, G. A. 1936 U. S. Pat. 2,038,679 (1936)

Runkel, Von Roland 0. H. 1949 Über die Herstellung von Zellstoff der Gattung Eucalyptus und Versuche mit zwei untershiedlichen Eucalyptusarten. Papier, 3: 476-490

Thode. E. F.. J. G. Bergomi. Jr., and R. E. Unson 1960 The application of a centrifugal water-retention test to pulp evaluation. Tappi, 49: 515-521

Thomas, B. B. 1966 Speciality papermaking with mercerized wood fibers. Tappi, 49: 515-521

Ward, K. Jr., 1960 Chemical modification of papermaking pulps. Tappi, 43: 54-59

Ward, K. Jr., M. L. Murray, A. J. Morak and M. H. Voelker 1967 Hydroxyethylation of linters pulps I. Hydroxyethylation with ethylene chlorohydrin and with ethylene oxide. Tappi, $\mathbf{5 0}: \mathbf{4 6 2 - 4 6 6}$

Ward, K. Jr., H. A. Swenson, W. A. Wink and R. J. Greisinger 1969 Improving the thermal stability of paper by chemical modification III. A study of hydroxyethylated pulps. Tappi, 52: 2336-2341 